\title{
Pigmentation after long-term topical use of adrenaline compounds
}

\author{
DAVID MOONEY \\ Royal Eye Hospital, London
}

The topical use of adrenaline and related compounds has been known to cause pigmentation of the conjunctiva since Löwenstein's observations (1927, 1930). Bietti (1938) and Marchesani and Ullerich (1950) described the histological appearance of the lesions and showed that they consisted of conjunctival inclusion cysts filled with melanin. Corwin and Spencer (1963) presented three cases of conjunctival melanin depositions and described the pathogenesis of the lesions. Blobner (1938) was the first person to report corneal pigmentation secondary to topical use of adrenaline and further cases have been described by Reinecke and Kuwabara (1963) and Zimmerman (1964), amongst others.

Spiers and Eldrup-Jørgensen (I966) reviewed 403 eyes treated with gutt. Eppy and found pigment deposits in $5^{8}$ ( 14 per cent.); the deposits were nearly always in the lower conjunctival fornix, being found only once in the upper fornix, and once in the bulbar conjunctiva. The earliest case occurred after 3 months of treatment.

The purpose of this paper is to report the incidence and sites of deposition of adrenaline pigmentation in patients attending the Glaucoma Glinic of the Royal Eye Hospital.

\section{Material and methods}

At the time of undertaking this survey there were 280 patients in the Glaucoma Clinic records and 147 of these had at some stage been using topical adrenaline compounds for glaucoma (either gutt. Eppy I per cent. or gutt. Lyophrin 2 per cent., and usually instilling the drops twice daily).

48 patients were unavailable for examination ( 14 were dead, 6 had transferred to other hospitals, 5 were too ill to attend, and 23 had ceased to attend the clinic and failed to reply to correspondence).

The cornea, bulbar conjunctiva, and upper and lower tarsal conjunctivae of each of the remaining 99 patients, consisting of 189 eyes, were examined with hand-held focal illumination for macroscopic deposits of pigment. The sites of pigment deposits were noted and the total number of months on adrenaline therapy recorded.

\section{Results}

Of the 189 eyes examined, 64 were found to have deposits of pigment (Table I).

\section{Table I Incidence of pigmentation}

\begin{tabular}{|c|c|c|c|c|}
\hline \multirow{2}{*}{$\begin{array}{l}\text { No. of eyes } \\
\text { examined }\end{array}$} & \multicolumn{2}{|c|}{ With pigmentation } & \multicolumn{2}{|c|}{ Without pigmentation } \\
\hline & No. & Per cent. & No. & Per cent. \\
\hline 189 & 64 & 34 & 125 & 66 \\
\hline
\end{tabular}


The sites of the deposits are shown in Table II. The relationship between the duration of adrenaline therapy and the presence of pigmentation is shown in Table III.

Table II Sites of pigmentation in 64 eyes

\begin{tabular}{lllll}
\hline $\begin{array}{l}\text { Lower tarsal conjunctiva } \\
\text { and lower fornix conjunctiva }\end{array}$ & $\begin{array}{l}\text { Upper tarsal } \\
\text { conjunctiva }\end{array}$ & $\begin{array}{l}\text { Bulbar } \\
\text { conjunctiva }\end{array}$ & Cornea \\
\cline { 1 - 2 } & 24 & 5 & 0 \\
\hline
\end{tabular}

Table III Pigmentation related to length of therapy in I 89 eyes

\begin{tabular}{|c|c|c|c|c|}
\hline \multicolumn{2}{|c|}{ Months of adrenaline therapy } & \multicolumn{2}{|c|}{ With pigmentation } & \multirow{2}{*}{$\begin{array}{l}\text { Without } \\
\text { pigmentation }\end{array}$} \\
\hline No. of months & No. of eyes & No. & Per cent. & \\
\hline Less than 9 & 29 & o & o & 29 \\
\hline 9 & 5 & I & 20 & 4 \\
\hline 10 & I & I & 100 & o \\
\hline I I & 9 & 3 & 33 & 6 \\
\hline 12 & 6 & I & 17 & 5 \\
\hline $13-15$ & 15 & 2 & I3 & 13 \\
\hline $16-20$ & 17 & 9 & 53 & 8 \\
\hline $21-30$ & 26 & 10 & 39 & 16 \\
\hline $3^{I-40}$ & 22 & 10 & 46 & 12 \\
\hline $4^{1-50}$ & 24 & 9 & 38 & 15 \\
\hline $5^{I-6 o}$ & 14 & 8 & 57 & 6 \\
\hline $61-70$ & II & 5 & 46 & 6 \\
\hline $71-80$ & 10 & 5 & 50 & 5 \\
\hline
\end{tabular}

\section{Discussion}

None of the patients on adrenaline therapy for less than 9 months had macroscopic deposits of pigment; however, of the 36 eyes on adrenaline for a total of 9 to 15 months (inclusive), eight (22 per cent.) had pigmentation and, of the 124 on adrenaline for 16 months or more, 55 (44 per cent.) had pigmentation. As can be seen from Table III, the incidence of pigmentation is fairly constant (varying from $3^{8}$ to 57 per cent.) after 16 months use of adrenaline, and this suggests that most of the patients who are prone to develop pigmentation will have done so after about 16 months' therapy.

Once a patient has developed pigmentation, the pigment deposits may remain unchanged for long periods of time in spite of stopping the adrenaline. Fig. I shows a photograph of the upper tarsal conjunctiva of a patient who was noted to have pigmentation after 22 months on adrenaline drops; the photograph was taken 2 years after the adrenaline had been stopped but the pigmentation is virtually unchanged.

Fig. 2 shows a clump of pigment projecting through the surface of the conjunctiva; this lesion has been observed over a period of 6 months and has remained unchanged and causes no symptoms. It is remarkable that these pigment deposits cause so little discomfort, bearing, as they do, such a close resemblance to calcific concretions. Only one 


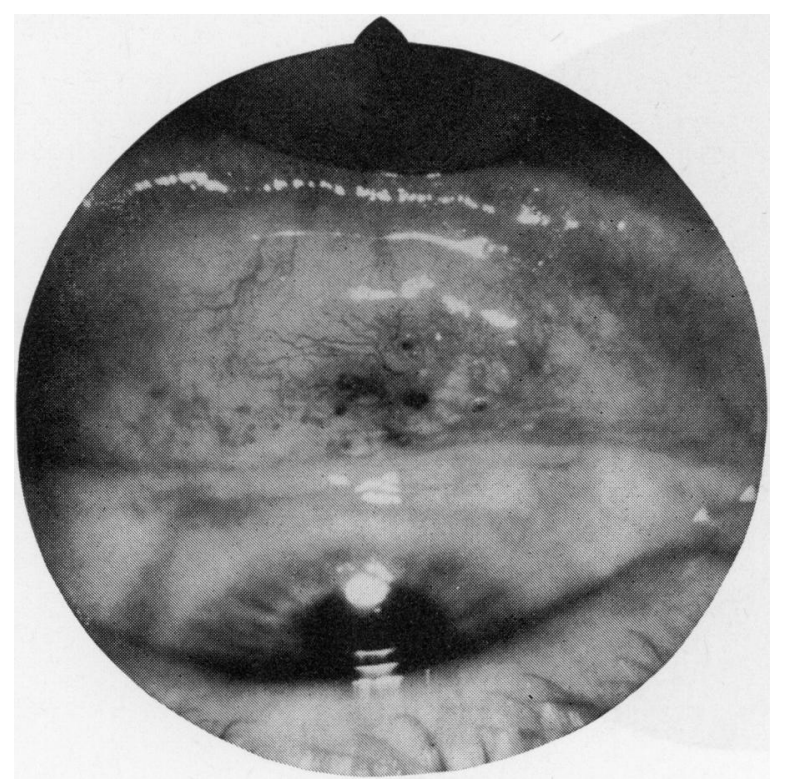

FIG. I Photograph of upper tarsal conjunctiva, showing pigmentation persisting 2 years after stopping adrenaline drops

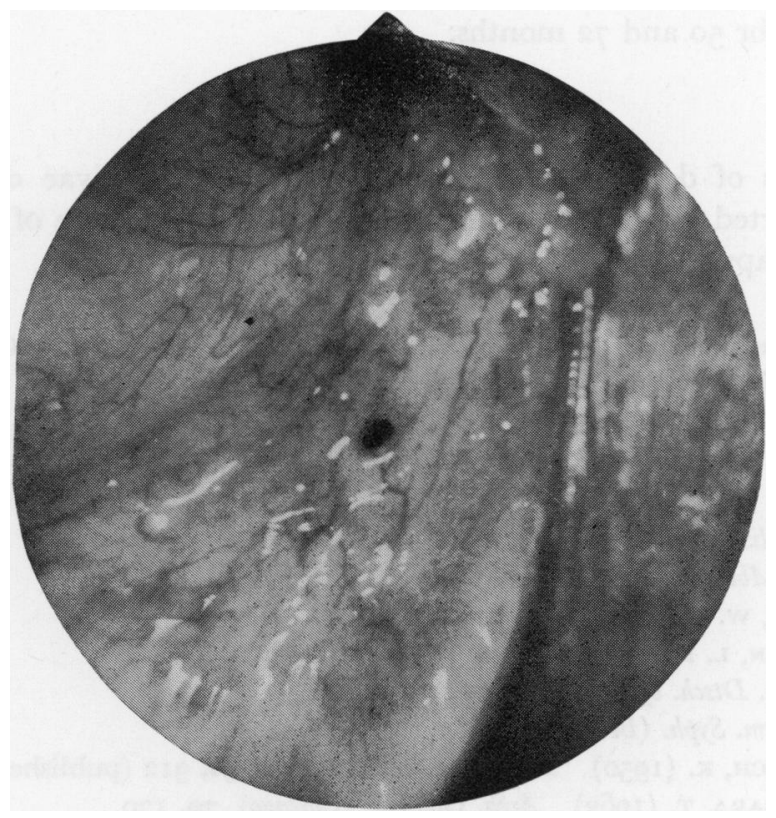

FIG. 2 Photograph showing a clump of pigment projecting from the conjunctiva but causing no symptoms

of our patients (Fig. 3) experienced irritation from the deposits and the lesions were easily excised under local anaesthesia in this case. It is felt that there is no indication for stopping the drops if pigmentation appears.

Pigmentation was twice as common in the lower as in the upper conjunctiva and only four cases of bulbar pigmentation were seen. It has been pointed out in the literature (Reinecke and Kuwabara, I963; Ferry and Zimmerman, 1964) that patients with corneal oedema may develop corneal pigmentation after prolonged use of adrenaline drops; two 


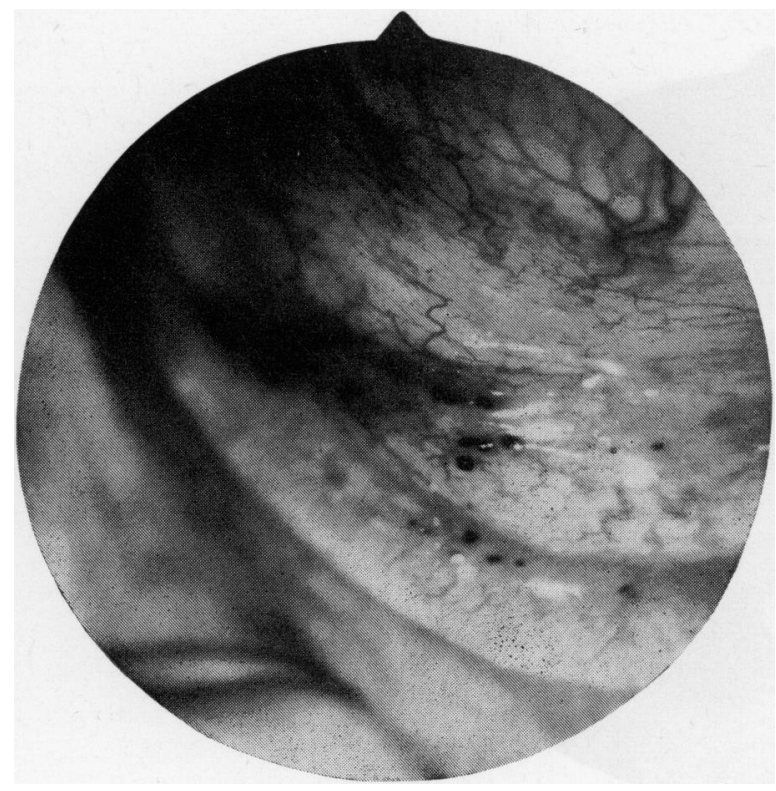

FIG. 3 Photograph of extensive pigmentation which caused mild symptoms and was readily excised

of our cases had corneal oedema but neither of them had corneal pigmentation in spite of having used adrenaline for 50 and 72 months.

\section{Summary}

The incidence and sites of deposition of melanin in the conjunctivae of patients on adrenaline drops is reported and the relationship between the incidence of pigmentation and the duration of therapy is discussed.

I wish to thank Mr. A. I. Friedmann, F.R.C.S., for his help and advice, and Miss F. Graham and her colleagues of the Glaucoma Clinic for their cooperation.

\section{References}

BIETTI, G. (1938) Boll. Oculist., 17, 65 BLOBNER, F. (1938) Klin. Mbl. Augenheilk., roo, $75^{8}$

CORWin, M. E., and SPENGER, W. H. (1963) Arch. Ophthal. (Chicago), 69, 317

FERRY, A. P., and zimMERMAN, L. E. (1964) Amer. F. Ophthal., 58, 205

LÖWENSTEIN, A. (1927) Ber. Dtsch. ophthal. Ges., 46, 439

(1930) Arch. Derm. Syph. (Berl.), 162, 180

marchesani, O., and Ullerich, K. (1950) Ber. Dtsch. ophthal. Ges., 56, $3^{12}$ (published i951)

REINEGKe, R. D., and KUWABARA, T. (1963) Arch. Ophthal. (Chicago), 70, i 70

SPIERS, F., and ELDRUP-JøRGENSEN, P. (1966) Trans. ophthal. Soc. U.K., 86, 255 